\title{
Prevalence and Characteristics of Traumatic Spinal Cord Injuries for Educational Hospitals in Cairo
}

\author{
HEBA G. SAYED, M.Sc. ${ }^{1}$; EMAN S. FAYEZ, Ph.D. ${ }^{2}$; AHMED A. SOLIMAN, M.D. ${ }^{3}$ and \\ AMINA AWAD, Ph.D. ${ }^{4}$ \\ The Department of Physical Therapy Emergency Hospital, Cairo University Hospitals ${ }^{1}$ \\ The Department of Physical Therapy for Neuromuscular Disorders and its Surgery, Faculty of Physical Therapy, \\ Cairo University ${ }^{2}$, The Department of Neurosurgery, Faculty of Medicine, Cairo University ${ }^{3}$ and \\ The Department of Physical Therapy for Neuromuscular Disorders and its Surgery, Faculty of Physical Therapy, Cairo University ${ }^{4}$
}

\begin{abstract}
Background: Traumatic Spinal Cord Injury (SCI) is a catastrophic event that is sudden and unexpected and can results in disturbances to normal sensory, motor, or autonomic function all of which can be devastating for the individual, both socially and economically. To our knowledge, local epidemiological study of traumatic SCI has not been carried out previously in Cairo.
\end{abstract}

Aim of Study: To identify the prevalence of common causes and characteristics of traumatic SCI among the population of Cairo.

Patients and Methods: Medical records of patients with traumatic SCI from Neurosurgery Department at Kaser AlAini Educational Hospital in Cairo, Egypt, were reviewed from the first of January 2017 to 31 December 2018. Demographic characteristics, etiology, neurological level were analyzed

Results: A total of 65 medical record of patients with traumatic SCI were reviewed during the mentioned period. The male to female ratio was 4.40:1. The mean age at injury was 32.18 years. The most frequent cause of traumatic SCI was falls $(49.2 \%)$, followed by traffic accidents $(43.1 \%)$. The neurological level of injury was $52.3 \%$ in cervical region, $30.8 \%$ in lumbar region and finally $16.9 \%$ in thoracic region.

Conclusion: Falls were the main causes of traumatic SCI among people living in Cairo with higher incidence to cervical lesion. Concerning gender, men have significantly higher rate of injury compared to women especially the young adult population. These information pose a challenge to the society health system to develop preventive strategies to SCI, improve the services and quality of life to Egyptian people living with SCI.

Key Words: Traumatic spinal cord injury - Etiology - Age Gender-Egypt-World health organization.

Correspondence to: Dr. Heba G. Sayed, The Department of Physical Therapy Emergency Hospital, Cairo University Hospitals

\section{Introduction}

TRAUMATIC Spinal Cord Injury (SCI) refers to multitude of injuries to the spinal cord, nerve roots, osseous structures, and disco-ligamentous components of the spinal column. Injuries may be secondary to blunt or penetrating trauma and result from both high and low energy mechanisms. Damage to the spinal column can lead to mechanical instability, pain and impaired mobility, while damage to neurological structures commonly results in partial or complete paralysis [1]. Trauma to the spinal cord remains a very serious condition with limited effective therapies. Early and delayed mortality rates are still high, and survivors sustain major functional impairments. Undoubtedly, injury prevention will always be the most efficacious strategy to diminish the societal impact of this condition [2].

The annual incidence of traumatic SCI in the Middle-East and North-Africa (MENA) Region was $23.24 /$ million. $77 \%$ of traumatic SCI cases were males with a mean age of 31.32 years. Furthermore, traffic accidents and falls were the leading causes of traumatic SCI. The thoracic region was the most common neurological level of injury among those population [3].

According to the World Health Organization (WHO) report in 2009, 746, 138 spinal cord injured cases were registered from Egyptian Ministry of Health Hospitals, of which $71.01 \%$ were males and $28.9 \%$ were females. The report revealed that leading causes of injury was road traffic injuries and the highest distribution of injuries occurred in ages 20 years to less than 30 year [4] so the purpose of this study was to identify the prevalence of 
common causes and characteristics of traumatic spinal cord injuries among Egyptian population.

\section{Patients and Methods}

A cross sectional single group related measurement survey study was held. The study included all traumatic SCI cases at the Department of Neurosurgry in Kaser Al-Aini Educational Hospital in Cairo during the period between the first of January 2017 and 31 st of December 2018. Data were collected from patients medical records through regular visits of the first author to Kasr Al-Aini Hospital.

\section{Inclusion criteria:}

The study were included patients with traumatic SCI [5] who got injured in last two years; between January 2017 and December 2018, with the age range from 16 to 60 years [6].

\section{Exclusion criteria:}

Patients with vertebral fractures and intervertebral disc disease without traumatic SCI, autoimmune disease, congenital anomaly, Multiple Sclerosis (MS), Motor Neuron Disease (MND), syringomylia or any other causes of cord injury were all excluded 5.

\section{Data analysis:}

The following information was extracted from the patient medical records: Sex, age, neurological level and cause of traumatic SCI.

\section{Statistical analyses:}

Numerical data was expressed as mean, minimum, maximum and Standard Deviation (SD). Categorical data was expressed as number (percent). Statistical Passage for Social Science (SPSS) program (version 20) was used in data analysis.

\section{Results}

Gender and age:

Gender and age distributions are shown in (Table 1$)$. On an average, $(81.5 \%)$ of the patients were male and $(18.5 \%)$ were female. The male/ female ratio was 4.40:1. Mean age of traumatic SCI was (32.18 \pm 12.15$)$ years, with a range of 1660 years. The age distribution had a peak at 21 to 40 years group, accounting for $(60 \%)$, followed by equal numbers of both adolescent ( $\leq 20 \mathrm{yrs}$.) and middle age adults (41-60 yrs.) [ 13 out of 65 $(20 \%)]$.

\section{Cause of injury:}

The results concerning the etiological cause of injury are presented in Fig. (1). The higher preva- lence appears for falls (49.2\%) and traffic accidents (43.1\%). Violence and sports accidents accounted for lower percent of SCI and represented $6.2 \%$ and $1.5 \%$, respectively.

\section{Neurological level of injury:}

The results of neurological level of traumatic SCI in the current study are represented in Fig. (2). Cervical spine injuries have accounted for $(52.3 \%)$ of all traumatic SCIs while lumbar spine injuries accounted for $(30.8 \%)$ and finally thoracic injuries accounted for $(16.9 \%)$ of all cases.

Table (1): Demographic features of the studied patients.

\begin{tabular}{llc}
\hline & Number & Precent (\%) \\
\hline Age (yrs.): & & \\
$\quad$ Minimum-maximum & $16-60$ & \\
$\quad$ Mean \pm SD & $32.18 \pm 12.15$ & \\
Adolescent ( $\leq 20)$ & 13 & 20.0 \\
Young adult (21-40) & 39 & 60.0 \\
Middle age adult (41-60) & 13 & 20.0 \\
Gender: & & \\
$\quad$ Female & 12 & 18.5 \\
$\quad$ Male & 53 & 81.5 \\
\hline
\end{tabular}

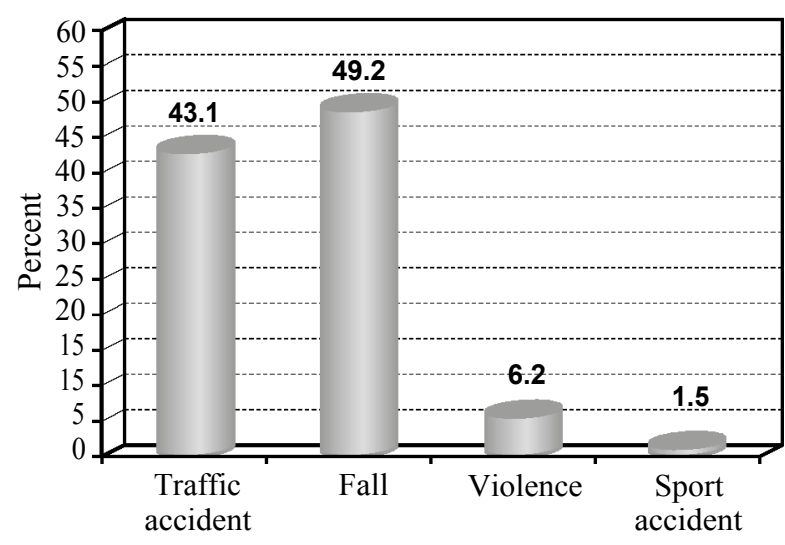

Fig. (1): Causes of trauma in the studied patients.

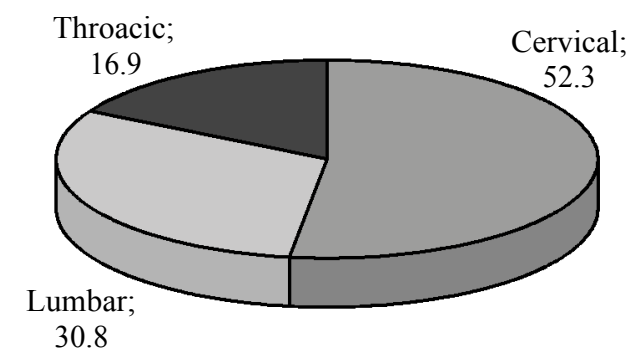

Fig. (2): Neurological level of injury in the studied patients.

\section{Discussion}

A detailed understanding of the epidemiological, and pathological features of traumatic SCI within local and a national system of care is vital to directing further system development, determining 
the priorities for funding and resource management, and identifying the greatest potential for injury prevention.

The current survey was performed on the traumatic SCI for patients referred to Kasr El-Ainy Educational Hospital during the period between January 2017 to December 2018. No figures have previously been available for the prevalence and characteristics of traumatic SCI in Cairo. This work has important implications for the prevention of traumatic SCI. Furthermore, employers should be aware of the potential of work-related SCI amongst employees who work at a height, and appropriate safety equipment should be provided.

The results of the present study revealed that the most frequent cause of traumatic SCIs was fall (49.2\%) followed by traffic accident (43.1\%), violence $(6.2 \%)$ and sport injury $(1.5 \%)$. It is similar to the results reported by ahoniemi and colleagues in 2008 were the most common cause of traumatic spinal injury was fall (41.2\%), followed by traffic accident $(39.5 \%)$ [7]. This study comes in agreement with the work of Mirzaeva and colleagues in 2019 who reported that the most frequent cause of traumatic SCI was falls (49.8\%), followed by motor vehicle accidents (18.9\%) [8] On the other hand, this study comes in disagreement with the work of Pickett and colleagues in 2006 who found that the most common causes of traumatic SCI were traffic accident (35\%) followed by falls $(31 \%)$ [9].

The results of the current study also showed that males $(81.5 \%)$ were at greater risk for traumatic SCI than females $(18.5 \%)$, with a male to female ratio of 4.40:1. The work of Ning and colleagues in 2011 agreed with findings of our study in which the authors found that $84.9 \%$ of the people suffering from traumatic SCI were males and $15.1 \%$ were females with male to female ratio of 5.63:1 [10] Furthermore, the results reported by knutsdottir in 2012 also agreed with our results, in which the majority of injured subjects were men. The findings of Knútsdóttir and authors were $72 \%$ male and $28 \%$ female suffered with traumatic spinal cord injuries [11]

Another finding of the current study was the high prevalence of cervical cord injury. The results showed that percent of individuals sustained an injury at the cervical level was $(52.3 \%)$, while $(30.8 \%)$ sustained an injury at lumbar level and finally (16.9) at thoracic level. These results study came in agreement with the work of Sabre and author, that reported the cervical part of spinal cord as the most common site of injury. In their report, Sabre and authors reported that the injury was $59.4 \%$ at cervical level, while $22.3 \%$ at lumbar level and $18.3 \%$ at thoracic level [12]. These results were similar to the result reported by Wang and Collegueas in 2013 in which most common site of injury were cervical level accounted for (46.3\%), followed by lumbar $(33.3 \%)$, then thoracic $(20.4 \%)$ [13]. On the other hand our study was contradictory to the work of Zhou in 2011 who found that lumbar spine was the most frequently involved (56.09\%), followed by thoracic spine $(23.77 \%)$, and cervical spine $(17.75 \%)$ [14].

Another important finding of the current study was that the majority of traumatic spinal cord injured people were young adult group (21-40 year old) and accounted for $(60 \%)$ of all patient with mean age equal to 32.18 , the study come in agreement with the work of Joseph and author in 2015 who reported that the peak incidence of traumatic SCI is within young adult group about $(82 \%)$ with a mean age equals (33.5) [15]. On the other hand, the present study came in disagreement with the work of Chen and collegueas in 2016 who found that the age group who was with the greatest percentage traumatic SCIs was the middle age adult group (41 to 60 -year-old) $(43.0 \%)$, followed by the young adult group (21 to 40 year-old) (39.6\%) and mean age of patient was (41.6) [5]

This work has a number of limitations. Firstly, lack of clear data about patient with traumatic SCIs as we have no information on patients who died before being referred to the Kaser Al-Aini Educational Hospital or were managed by other hospitals. Second, the small sample size could be limitation due to the mentioned causes above in addition to collecting data from a limited geographical area over only two years. These limitations may preclude comprehensive statistical interpretation of the results.

\section{Conclusion:}

The current work provided a contemporary descriptive measure of the characteristics and nature of traumatic SCI treated with hospitalization among Egyptian population living in Cairo. The study revealed that the groups who are at the highest risk for injury were the young adult between 21-40 (mean age 32.18). Furthermore, falls are approaching motor vehicle accidents as the most common causes of traumatic SCI in Cairo with $49 \%$ affecting the cervical spine. Although traumatic SCI is predominantly present in men, more attention for primary prevention, medical care and rehabilitation in men and women is needed. Future public health 
efforts need to expand their focus to include strategies for prevention of falls, reducing road traffic injuries, and increasing awareness of the need for improved work safety among Egyptian people.

\section{Conflict of interest:}

The authors declare no conflict of interest.

\section{References}

1- KUMAR R., LIM J., MEKARY R.A., RATTANI A., DEWAN M.C., SHARIF S.Y. and PARK K.B.: Traumatic spinal injury: Global epidemiology and worldwide volume. World Neurosurgery, 2018.

2- RABINSTEIN A.A.: Traumatic spinal cord injury. CONTINUUM: Lifelong Learning in Neurology, 24 2, Spinal Cord Disorders), 551-66, 2018

3- ELSHAHIDI M.H., MONIR N.Y., ELZHERY M.A., SHARAQI A.A., HAEDAYA H., AWAD B.I. and ZAGHLOUL K.: Epidemiological characteristics of traumatic spinal cord injury (TSCI) in the Middle-East and NorthAfrica (MENA) Region: A systematic review and metaanalysis. Bulletin of Emergency \& Trauma, 6 (2): 75 , 2018.

4- World Health Organization: "Department of Violence and Injury Prevention and Disability". In Global Status Report on Road Safety: Time for Action, Geneva, Switzerland: World Health Organization, 2009.

5- CHEN K., TANG Y., YANG R., LU C., WU Y., GUO L. and CAI Z.: Epidemiological Characteristics of Traumatic Spinal Cord Injury in Guangdong, China. Spine, 42 (9) E555-E561, 2016.

6- KENNEDY P. and CHESSELL Z.J.: Traumatic versus non-traumatic spinal cord injuries: Are there differential rehabilitation outcomes? Spinal Cord, 51 (7): 579, 2013.

7- AHONIEMI E., ALARANTA H., HOKKINEN E.M., VALTONEN K. and KAUTIAINEN H.: Incidence of traumatic spinal cord injuries in Finland over a 30-year period. Spinal Cord, 46 (12): 781-4, 2008.

8- MIRZAEVA L., GILHUS N.E., LOBZIN S. and REKAND T.: Incidence of adult traumatic spinal cord injury in Saint Petersburg, Russia, 2019.

9- PICKETT G.E., CAMPOS-BENITEZ M., KELLER J.L. and DUGGAL N.: Epidemiology of traumatic spinal cord injury in Canada. Spine, 31 (7): 799-805, 2006.

10- NING G., YU T., FENG S., ZHOU X., BAN D., LIU Y. and JIAO X.: Epidemiology of traumatic spinal cord injury in Tianjin, China, 2011.

11- KNÚTSDÓTTIR S., THÓRISDÓTTIR H., SIGVALDASON K., JÓNSSON H., BJÖRNSSON A. and INGVARSSON P.: Epidemiology of traumatic spinal cord injuries in Iceland from 1975 to 2009. Spinal Cord, 50 (2): 123 6, 2012.

12- SABRE L., PEDAI G., REKAND T., ASSER T., LINNAMÄGI and KÕRV J.: High incidence of traumatic spinal cord injury in Estonia, 2012.

13- WANG H.F., YIN Z.S., CHEN Y., DUAN Z.H., HOU S and HE J.: Epidemiological features of traumatic spinal cord injury in Anhui Province, China, 2013.

14- ZHOU J., CHAO R., WANG Z., ZHAO J., LIU Y., YAO Y. and LIU P.: Spinal Trauma in Mainland China From 2001 to $2007,2011$.

15- JOSEPH C., DELCARME A., VLOK I., WAHMAN K., PHILLIPS J. and NILSSON WIKMAR L.: Incidence and aetiology of traumatic spinal cord injury in Cape Town, South Africa: A prospective, population-based study. Spinal Cord, 53 (9): 692-6, 2015.

\title{
دراسة إنتشاروخصائص إصابات الحبل الشوكى

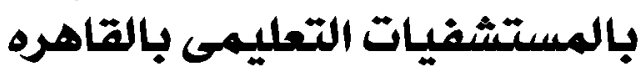

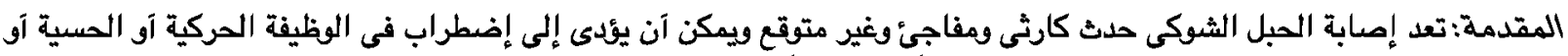

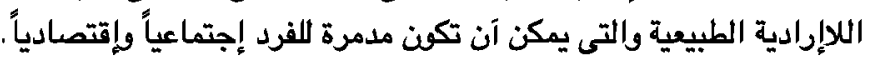 \\ الهدف من هذه الدراسة: تحديد خصائص إصابة الحبل الشوكى والآسباب المؤديه لها بين سكان القاهره.

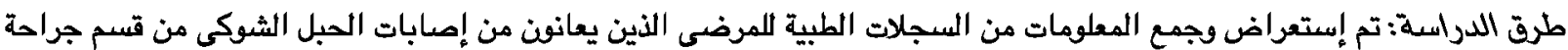

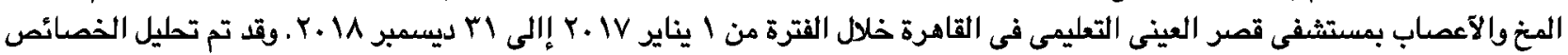

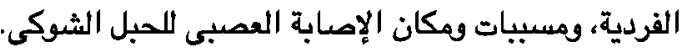

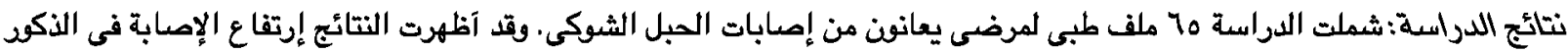

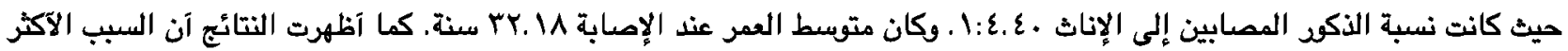

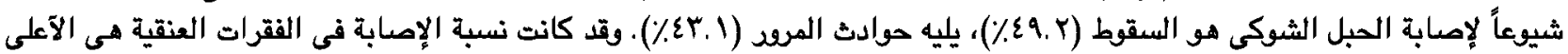

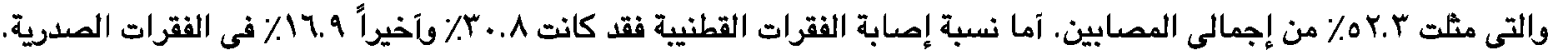

